\title{
Microstructure and mechanical properties at elevated temperatures of a new Al-containing refractory high- entropy alloy $\mathrm{Nb}-\mathrm{Mo}-\mathrm{Cr}-\mathrm{Ti}-\mathrm{Al}$
}

\author{
H. Chen ${ }^{a \star}$, A. Kauffmann ${ }^{a}$, B. Gorr ${ }^{b}$, D. Schliephake ${ }^{a}$, C. Seemüller ${ }^{a}$, J. N. Wagner ${ }^{a}$, \\ H.-J. Christ ${ }^{b}$, and M. Heilmaier ${ }^{a}$ \\ a Institute for Applied Materials (IAM-WK), Karlsruhe Institute of Technology (KIT), \\ Engelbert-Arnold-Str. 4, D-76131 Karlsruhe, Germany \\ ${ }^{b}$ Institut für Werkstofftechnik, Universität Siegen, Paul-Bonatz-Str. 9-11, D-57068 \\ Siegen, Germany \\ * corresponding author \\ mail: hans.chen@kit.edu, phone: +4972160846462
}

Keywords: high-entropy alloys, refractory metals, homogenization, deformation, secondary phases

\section{Abstract}

2 In the present investigation, we provide results on the casting, homogenization, and 3 deformation behavior of a new Al-containing refractory high-entropy alloy, namely the 4 equiatomic $\mathrm{Nb}-\mathrm{Mo}-\mathrm{Cr}-\mathrm{Ti}-\mathrm{Al}$. The alloy shows a dendritic microstructure after arc melting. 5 The dendrites completely dissolve due to a heat treatment at $1300{ }^{\circ} \mathrm{C}$ for $20 \mathrm{~h}$. Besides a major phase in the form of a solid solution of $\mathrm{W}$ prototype structure, identified by X-ray diffraction (XRD) measurements as well as electron backscatter diffraction (EBSD), additional phases of small volume fraction within the grains and at the grain boundaries were observed. Quasistatic compression tests, performed between room temperature and $1200{ }^{\circ} \mathrm{C}$, reveal sustaining and high yield strength up to $800{ }^{\circ} \mathrm{C}$ and an increasing ductility with increasing test temperature. The dominant deformation mechanism for quasistatic compression loading between $800{ }^{\circ} \mathrm{C}$ and $1200{ }^{\circ} \mathrm{C}$ is the $\langle 111\rangle$ pencil glide of dislocations within the solid solution which was proven by the according fiber texture components, evolving during deformation.

\section{Introduction}

Materials, combining excellent mechanical strength at ambient as well as elevated temperature with a suitable ductility and toughness, always are a reasonable optimization goal of modern materials science in order to facilitate new applications in mechanical engineering. In this respect, the recently proposed concept of suppression of intermetallic phases and stabilization of a solid solution of simple crystal structure by minimizing the configurational 
entropy term $-\mathrm{T} \cdot \Delta \mathrm{S}_{\text {config }}$ in the Gibb's free energy [1-5] seems to provide an approach. For this purpose, equiatomic concentrations of mainly at least five alloying elements should be established in the solid solution in order to fulfill this concept. Due to the suppression of brittle intermetallic phases, ductility can in principle be improved. This is, of course, a rough assumption when the typical embrittlement of body-centered cubic (bcc) solid solutions with respect to the ductility and toughness of the base elements (for example Mo-Si or Mo-Re [68]) is taken into account. Nevertheless, Senkov \& Semiatin [9] recently presented a bcc high entropy alloy which could be rolled up to a remarkable true strain of about 2.3 at room temperature indicating that a simple extrapolation from binary or ternary solid solutions to concentrated multicomponent systems with respect to ductility and toughness can be misleading. In addition to the suppression of intermetallic phases, choosing base elements with high melting points can lead to an enhanced melting point of the high-entropy alloy in comparison to currently used high temperature materials. Thus, operation at higher temperature is in principle possible. Moreover, adding alloying elements for improving properties other than pure mechanical ones is possible, too - for example, by utilizing elements facilitating the formation of a stable oxide scale for enhancing high temperature corrosion resistance.

Before adding Al, the focus has mainly been on the microstructure, mechanical properties and oxidation behavior of high-entropy alloys, solely based on elements with high melting points from group 4 to 6 (frequently named refractory metals) of the periodic table of elements [1012]. Due to the high density of these alloys ranging up to $13.75 \mathrm{~g} / \mathrm{cm}^{3}$ for equiatomic $\mathrm{W}-\mathrm{Nb}$ Mo-Ta, heavy elements were replaced by lighter ones such as $\mathrm{Hf}, \mathrm{Zr}, \mathrm{Cr}$ and $\mathrm{Ti}$ [6,13-20]. The addition of $\mathrm{Al}$ to a high-entropy alloy changes its properties in different ways. With increasing Al content, the density of the alloy decreases. Comparing the alloys Ta-Nb-Hf-Zr-Ti and $\mathrm{Al}_{0.4}-\mathrm{Hf}_{0.6}-\mathrm{Nb}-\mathrm{Ta}-\mathrm{Ti}-\mathrm{Zr}$ which were introduced by Senkov et al. [20,21], the density drops from about $9.9 \mathrm{~g} / \mathrm{cm}^{3}$ to $9.0 \mathrm{~g} / \mathrm{cm}^{3}$. The mechanical properties, such as the yield strength and the ductility, depend on the amount of $\mathrm{Al}$ in the HEA, investigated on Nb-Ti-V-Ta- $\mathrm{Al}_{\mathrm{x}}$ [22] and $\mathrm{Al}_{\mathrm{x}}-\mathrm{Hf}-\mathrm{Nb}-\mathrm{Ta}-\mathrm{Ti}-\mathrm{Zr}$ [23]. Regarding high temperature oxidation, Al may form a stable and dense $\mathrm{Al}_{2} \mathrm{O}_{3}$ oxide scale. Oxidation tests of the high-entropy alloy W-Mo-Al-Cr-Ti reveal a scale growth following the parabolic growth law [24]. Having a similar atomic radius as refractory metals, it can be expected that Al-addition allows the formation of a solid solution in such an alloy, thus preventing the formation of intermetallic phases [21]. Nevertheless, it has to be pointed out that several investigations already revealed various parameters other than the configurational entropy or atomic size difference to be more or less decisive, such as the mixing enthalpy $\Delta \mathrm{H}_{\text {mix }}$, the mixing entropy $\Delta \mathrm{S}_{\text {mix }}$ [25], the parameter $\Omega$ which describes the correlation between $\Delta \mathrm{H}_{\text {mix }}$ and $\Delta \mathrm{S}_{\text {mix }}$ [26], and the valence electron concentration VEC [27]. Hence, the stability of a solid solution with simple crystals structure has to be verified for each case.

In the present work, $\mathrm{Nb}-\mathrm{Mo}-\mathrm{Cr}-\mathrm{Ti}-\mathrm{Al}$ is investigated with respect to microstructural evolution 60 during annealing as well as mechanical properties at various temperatures. For that, $\mathrm{Nb}, \mathrm{Mo}$ 
application. Ti, again, and $\mathrm{Al}$ are chosen in order to achieve low density, as shown by Senkov et al. [13,21], while $\mathrm{Al}$ and $\mathrm{Cr}$ are considered due to their ability to form stable oxide scales for good oxidation resistance. Nb-Mo-Cr-Ti-Al is expected to have similar properties as the W-containing counterpart, introduced above. CALPHAD calculations suggest that Nb-MoCr-Ti-Al ("PanNb with V" database using Pandat; single phase, solid solution at 788$1712^{\circ} \mathrm{C}$ ) exhibits a similar melting temperature as W-Mo-Cr-Ti-Al (FactSage calculation; single phase, solid solution at $1077-1700{ }^{\circ} \mathrm{C}$ [24]). Considering the lower atomic mass of $\mathrm{Nb}$, a lower density is to be expected when comparing Nb-Mo-Cr-Ti-Al with W-Mo-Cr-Ti-Al.

Generally, the investigated alloys show dendritic structure in the as-cast condition with significant differences in atomic concentration between dendritic and interdendritic regions [24,28]. An annealing step is typically performed after casting in order to homogenize the microstructure as well as to establish a single phase solid solution with simple crystal structure [13,14]. Despite the theory of stabilization of solid solutions by increasing the configurational entropy, a macro- and mesoscopically homogeneous microstructure cannot be reached in all cases of postulated high-entropy alloys. This is even more evident when investigations down to atomic scale are performed [29]. In addition to these local investigations, secondary phases are frequently found. XRD patterns of Ta-Nb-Hf-Zr-Ti show a presumably hexagonal second phase besides the main body-centered cubic structure (bcc) whereas $\mathrm{Cr}-\mathrm{Nb}-\mathrm{Ti}-(\mathrm{V}-) \mathrm{Zr}$ exhibits a $\mathrm{Cr}$-rich face-centered cubic Laves phase $[13,15]$.

In this publication, a detailed characterization of the alloy $\mathrm{Nb}-\mathrm{Mo}-\mathrm{Cr}-\mathrm{Ti}-\mathrm{Al}$ is presented, especially regarding microstructure, its evolution after heat treatment, and deformation at ambient and elevated temperature. Furthermore, the deformation mechanism by dislocation slip during compression loading at elevated temperatures is explicitly examined and identified by EBSD analysis.

\section{Experimental}

Nb-Mo-Cr-Ti-Al was melted from elemental bulk materials, mixed in equiatomic concentration, using an arc-melter AM/0.5, provided by Edmund Bühler GmbH. The purities of the starting materials $\mathrm{Nb}, \mathrm{Mo}, \mathrm{Al}, \mathrm{Cr}$ and $\mathrm{Ti}$ were $99.9 \%, 99.96 \%, 99.9 \%, 99 \%$, and $99.8 \%$, respectively. The Ar base pressure for arc-melting was 0.6 bar following several alternating iterations of pumping and Ar flooding. A $\mathrm{Zr}$ lump in the vacuum chamber was used in order to reduce residual oxygen by liquefying prior to every melting step. The prepared buttons were flipped and remelted for at least five times for homogenization. After the final melting step, the alloy was cast into a rod-shaped $\mathrm{Cu}$ mold. The diameter and the length of the cast rod were $12 \mathrm{~mm}$ and $60 \mathrm{~mm}$, respectively. The chemical alloy composition was analyzed using inductively coupled plasma optical emission spectrometry (ICP-OES) for the elements $\mathrm{Nb}, \mathrm{Mo}, \mathrm{Cr}$, Ti and $\mathrm{Al}$. O and $\mathrm{N}$ content were determined by means of carrier gas hot extraction analysis, using a TC500 by Leco. Heat treatments were performed using a Gero HTRH 70-600/18 resistance heating tube furnace under Ar flow at 1100, 1200, and 
$1001300{ }^{\circ} \mathrm{C}$ for $20 \mathrm{~h}$. The heating and cooling rate were $4.2 \mathrm{~K} / \mathrm{min}$. The platelet shaped samples

101 with $12 \mathrm{~mm}$ in diameter were extracted from one and the same cast sample.

102 The cast as well as the heat-treated alloy conditions were investigated by means of SEM

103 utilizing backscatter electron (BSE) imaging and energy dispersive X-ray spectroscopy 104 (EDX) as well as EBSD for analytical purposes. All samples were prepared by a standard metallographic procedure finalized by a vibratory polishing step, using a non-crystallizing oxide polishing suspension with $\mathrm{pH}=9.8$, provided by Struers. Thereby, a combination of mechanical and chemical preparation was achieved. SEM investigations were performed on a Zeiss Auriga dual beam scanning electron and focused ion beam microscope equipped with an EDAX DigiView EBSD system and EDAX Octane silicon drift detector EDX system as well as a Zeiss EVO50 system equipped with a Thermo Scientific EDX system. X-ray diffraction analyses were carried out on a D2 Phaser system by Bruker equipped with a Lynxeye line detector. The $\mathrm{Cu}$ tube was operated at $30 \mathrm{kV}$ and $10 \mathrm{~mA}$. Quasistatic compression tests were performed utilizing a Zwick Z100 electro-mechanical universal testing machine equipped with a vacuum furnace by Maytec. After heating at a rate of $20 \mathrm{~K} / \mathrm{min}$, the test temperature was stabilized for $30 \mathrm{~min}$ before testing. The heat-treated samples $\left(1300^{\circ} \mathrm{C} / 20 \mathrm{~h}\right)$ of $(3 \times 3 \times$ 4.5) $\mathrm{mm}^{3}$ were tested under vacuum with an initial engineering strain rate of $10^{-3} \mathrm{~s}^{-1}$. Strain was determined using strain gauges attached to the samples. The punches were made of $\mathrm{SiC}$ and hexagonal $\mathrm{BN}$ was used for lubrication. The specimens for compression tests shown in this article were extracted from the same cast sample as the specimens for heat-treatment experiments. For the reproduction of the deformation experiments, a second batch of material was produced and treated in the same way as described before.

\section{Results and discussion}

\subsection{Casting and homogenization}

124

125

126

127

128

129

130

131

132

133

134

135

136

Tab. 1 summarizes the chemical composition of the different materials conditions investigated in this article. For the as-cast state, wet chemical analysis by ICP-OES and EDX are in good agreement and the deviation from the equimolar composition does not exceed 0.75 at $\%$ for all elements. Hence, there is little evaporation during arc melting operations despite large differences in melting and boiling point of the alloying elements. The microstructure of the as-cast state, as it is shown in Fig. 1a, consists of dendritic and interdendritic regions within a polycrystalline matrix. Even at high resolution, no evidence for secondary phases was found. Previous investigations revealed that elements with high melting points tend to crystallize in the early stages of solidification [19,28]. In accordance to that, EDX of the dendrites reveals enrichment in Mo and $\mathrm{Nb}$ during primary solidification (Tab. 1). In contrast, the interdendritic regions are enriched in $\mathrm{Cr}$, $\mathrm{Ti}$ and $\mathrm{Al}$. By analyzing the compositions of the dendritic and inter-dendritic regions in comparison to the total composition, fractions of 46 at $\%$ dendritic as well as 54 at\% inter-dendritic region can be calculated, respectively. The XRD analysis of the 
as-cast state is shown in Fig. 2. The major Bragg positions can be assigned to a bcc crystal structure of the $\mathrm{W}$ prototype with a broad variation of possible lattice constants ranging from about $0.312 \mathrm{~nm}$ up to $0.318 \mathrm{~nm}$. The variation is most probably attributed to the inhomogeneous element distribution within the solid solution as it was assumed in previous investigations [24], too. This can be well described by assuming several bcc phases with different lattice parameters. The obtained values are slightly higher than those of the comparable W-Mo-Al-Cr-Ti alloy, which are between about $0.309 \mathrm{~nm}$ and $0.312 \mathrm{~nm}$ (for the as-cast as well as heat-treated condition) [24]. Considering the larger atomic radius of $\mathrm{Nb}$ (145 pm) compared to $\mathrm{W}(135 \mathrm{pm})$, an increase of the lattice parameter in $\mathrm{Nb}-\mathrm{Mo}-\mathrm{Cr}-\mathrm{Ti}-\mathrm{Al}$ is conceivable [30]. Local analysis of the crystal structure of dendritic and interdendritic regions within a single grain of the as-cast state (patterns are included in the online supplementary, similar pattern to that in Fig. 3d), respectively, support the global XRD analysis by patterns of bcc crystals with minor changes of the lattice constant (the determined variation of 0.312 $0.318 \mathrm{~nm}$ is below the resolution of the EBSD camera system in use).

In order to homogenize the material as well as to establish a single phase solid solution, heat treatments of $20 \mathrm{~h}$ under Ar atmosphere were performed. The microstructure following an annealing at $1100{ }^{\circ} \mathrm{C}$ does not exhibit a significant homogenization effect which can be seen from microstructural imaging in Fig. $1 \mathrm{~b}$ as well as global XRD analysis in Fig. 2. In Fig. 1b, a combination of composition and orientation contrast is visible. The local analysis of crystal structure reveals at least three different phases that can be identified as bcc (W prototype, Strukturbericht designation A2, pattern is included in the online supplementary, similar to the pattern in Fig. 3d), the hexagonal modification of the $\mathrm{Cr}_{2} \mathrm{Nb}$ Laves phase $\left(\mathrm{MgZn}_{2}\right.$ prototype, Strukturbericht designation C14, Fig. 3a) and an unknown phase (Fig. 3b). Due to the small length scale of the obtained microstructure, a detailed investigation of the local chemistry of the phases by SEM-EDX is not suitable, here. This is done for higher annealing temperatures in the following.

Subsequent to a heat treatment at $1200{ }^{\circ} \mathrm{C}$, the volume fraction of dendritic microstructure was significantly reduced as visualized in Fig. 1c. Also, the number and intensity of Bragg positions, not correlating with those of the bcc crystal structure, are significantly reduced, as seen in the XRD pattern in Fig. 2a. The secondary phases are mainly located at the grain boundaries. The Laves phase, which was identified by electron diffraction (pattern is included in the online supplementary, similar to the pattern in Fig. 3a), appears dark-gray and an unknown phase (Fig. 3c) appears bright in the inset of Fig. 1c. The diffraction pattern of the unknown phase in Fig. 3c exhibits remarkable similarities to the pattern for the unknown phase (Fig. 3b, indicated by arrows connecting similar zone axis) obtained following the $1100{ }^{\circ} \mathrm{C}$ annealing step. Thus, the unknown phase obtained subsequent to annealing at $1100{ }^{\circ} \mathrm{C}$ and $1200^{\circ} \mathrm{C}$ seem to be the same. The grain size of the solid solution (W prototype, see pattern in Fig. 3d) has grown to $50-100 \mu \mathrm{m}$ as it can be seen from the SEM image in Fig. 1d. According to Tab. 1, the solid solution approximately exhibits the equimolar composition with deviations less than 0.6 at $\%$. By analyzing the compositions of the obtained phases in comparison to the total composition, the fraction of the solid solution can be 
calculated to about 87 at\%, which is in good agreement with the SEM image in Fig. 1c. The hexagonal Laves phase is enriched in $\mathrm{Cr}$. The presence of a $\mathrm{Cr}$-rich Laves phase was already observed in the alloys $\mathrm{Cr}-\mathrm{Nb}-\mathrm{Ta}-\mathrm{Ti}-\mathrm{Zr}$ and $\mathrm{Cr}-\mathrm{Nb}-\mathrm{Ti}-\mathrm{V}-\mathrm{Zr}$ [13,19]. However, the reported Laves phases were identified as the face-centered cubic modification of $\mathrm{Cr}_{2} \mathrm{Nb}\left(\mathrm{MgCu}_{2}\right.$ prototype, Strukturbericht designation $\mathrm{C} 15)$. A possible substitution of lattice sites can be described by means of $(\mathrm{Cr}, \mathrm{Al}, \mathrm{Mo})_{2}(\mathrm{Nb}, \mathrm{Ti})$ according to the overall composition of the phase: (i) ideal stoichiometry $\mathrm{Cr}: \mathrm{Nb}=66.6: 33.3$ and (ii) present sample $(\mathrm{Cr}, \mathrm{Al}, \mathrm{Mo}):(\mathrm{Nb}, \mathrm{Ti})=$ 65.3:34.7 (see Tab. 1). Since the composition as well as crystallographic data suggest a derivation of the present Laves phase from the binary $\mathrm{Cr}_{2} \mathrm{Nb}$, the following discussion is based on the relation of these two elements to the others present in the HEA. $\mathrm{Cr}-\mathrm{Nb}$ as well as $\mathrm{Cr}$-Ti form Laves phases. Nb-Ti as well as Cr-Mo exhibit complete solubility (Cr-Mo with miscibility gap at low temperature). Al-Cr forms a $\mathrm{Cr}_{2} \mathrm{Al}$ compound but the prototype system is not related to a Laves phase ( $\mathrm{MoSi}_{2}$ prototype). It has to be emphasized, that Mo-Nb exhibit complete solubility in contrast to the proposed substitution. Thus, a certain amount of Mo on the $\mathrm{Nb}$ lattice site is to be expected, too. The XRD pattern shows a Bragg position at $25.22^{\circ}$, which can perhaps be assigned to the unknown phases (Fig. 3b and c). The EDX analysis does not provide indications for a suitable stoichiometric prototype structure since it exhibits a similar composition as the solid solution.

A further increase of homogenization temperature up to $1300{ }^{\circ} \mathrm{C}$, as shown in Fig. 1d, results in a further reduction of secondary phases within the grains of the solid solution. The contrast of Fig. 1d is mainly attributed to different orientations of the chemically homogeneous grains. The chemical composition of the bcc solid solution (diffraction pattern in Fig. 3d) is shown in Tab. 1. The deviation from the equimolar composition is less than 0.5 at $\%$. Residual intermetallic phases are found in the vicinity of the grain boundaries similar to observations on comparable Al-containing refractory high-entropy alloys in Ref. [21]. Hence, Bragg positions, not assignable to the bcc crystal structure, are still present as they are visualized in the logarithmic intensity plot in Fig. 2b. Evidence for the local appearance of any modification of the Laves phases was not found. The grain boundaries seem to be decorated by the unknown phase, exclusively. The pattern of the unknown phase in Fig. 3e differs from those observed for annealing at 1100 and $1200{ }^{\circ} \mathrm{C}$ (Fig. $3 \mathrm{~b}$ and c). Based on image analysis the fraction of secondary phase at the grain boundary could be determined to be well below $0.5 \mathrm{vol} \%$ while the spread of the acicular morphology into the matrix grains is always below $10 \mu \mathrm{m}$ (inset of Fig. 1d). The grain size of the bcc solid solution increased to about $250 \mu \mathrm{m}$. Abnormal grain growth has already started. A further increase of homogenization temperature to maximum $1400{ }^{\circ} \mathrm{C}$ does not lead to a full suppression of secondary phases but further rapid grain growth is observed (not shown here). In order to provide a reasonable orientation distribution during the following analysis of the microstructure subsequent to quasistatic compression tests, the following results were obtained on samples, homogenized at $1300{ }^{\circ} \mathrm{C}$ for $20 \mathrm{~h}$. 


\subsection{Deformation at ambient and elevated temperature}

218 In order to evaluate the potential of the present $\mathrm{Nb}-\mathrm{Mo}-\mathrm{Cr}-\mathrm{Ti}-\mathrm{Al}$ alloy regarding high 219 temperature application, compression tests were performed at room temperature, $400{ }^{\circ} \mathrm{C}$, $220600{ }^{\circ} \mathrm{C}, 800{ }^{\circ} \mathrm{C}, 1000{ }^{\circ} \mathrm{C}$ and $1200{ }^{\circ} \mathrm{C}$ with a strain rate of $10^{-3} \mathrm{~s}^{-1}$. Fig. 4 shows the according 221 stress-strain dependence and Tab. 2 summarizes the mechanical properties determined by 222 these tests.

At room temperature, there was no indication of plastic deformation. At elevated temperatures, plastic deformation was observed. A minimum fracture strain of 0.02 was reached at $400{ }^{\circ} \mathrm{C}$. While strength remains stable, plastic deformability before failure rises up to 0.135 by increasing the temperature to $800{ }^{\circ} \mathrm{C}$. Beside a significant drop of stress by $40 \%$ at $1000{ }^{\circ} \mathrm{C}$, stress-strain dependence shows a characteristic curve shape with an inflection point after reaching maximum stress. At $1200{ }^{\circ} \mathrm{C}$, a plastic strain of over 0.24 without indication of internal cracks was obtained.

Regarding room temperature compression test, onset of plasticity could not be determined unlike to comparable Al-containing high-entropy alloys, such as $\mathrm{Al}-\mathrm{Nb}_{1.5}-\mathrm{Ta}_{0.5}-\mathrm{Ti}_{1.5}-\mathrm{Zr}_{0.5}$ which revealed a plastic strain of at least 0.035 at room temperature [21]. The maximum stresses during compression tests up to $800{ }^{\circ} \mathrm{C}$ are most probably determined by defects of the cast material as it can be exemplarily seen in the SEM micrographs in Fig. 1d. Thus, a large standard deviation of the characteristic stresses is observed at a test temperature of $800{ }^{\circ} \mathrm{C}$ (Tab. 2). As regularly seen in literature [14,16,21], temperature increase leads to higher plasticity. At $1000{ }^{\circ} \mathrm{C}$, the investigated alloy shows a similar curve shape as high-entropy alloys by Senkov et al. [21], tested in the same temperature range. Dynamic recrystallization as a possible reason for the softening behavior [31] can be excluded since no evidence for microstructure restoration by nucleation at the grain boundary forming typical necklace structures or particle stimulated nucleation was found (Fig. 5d).

After performing the quasistatic compression tests, microstructure of the deformed samples was analyzed by means of EBSD. Therefore, orientation maps are shown in Fig. 5 as colorcoded images according to the inverse pole figure (inset in Fig. 5b) of the compression direction (CD). Abnormal grain growth induced during the homogenization process is clearly indicated by grains with diameter of more than $500 \mu \mathrm{m}$ in the as-homogenized state. Subsequent to deformation at $400{ }^{\circ} \mathrm{C}$, cracks are observed with an orientation of about $45^{\circ}$ with respect to the compression direction. Discontinuous stress-strain dependence during loading at $400{ }^{\circ} \mathrm{C}$ as well as $600{ }^{\circ} \mathrm{C}$ is caused by crack initiation within the material, which is exemplarily seen in Fig. 5b. In the vicinity of the crack, increased local misorientation is observed, revealing localized plastic deformation. In contrast, short cracks are oriented parallel to the compression direction and local misorientation is homogeneously distributed at $800{ }^{\circ} \mathrm{C}$. In all cases, $400{ }^{\circ} \mathrm{C}, 600{ }^{\circ} \mathrm{C}$ and $800{ }^{\circ} \mathrm{C}$, occurring cracks are transgranular, implying stable grain boundaries within the material. At $1000{ }^{\circ} \mathrm{C}$ as well as $1200{ }^{\circ} \mathrm{C}$, cracks are absent, plastic deformation occurs uniformly, and grains become flattened as it is expected for ductile behavior during compression tests. In this temperature range, significant changes of the 
microstructure were observed during the solution annealing experiments. Thus, further analysis of changing microstructure and phases were performed after thermomechanical loading. In contrast to deformation tests at $800{ }^{\circ} \mathrm{C}$ and below, the phases at the grain boundaries of the as-homogenized microstructure tend to coarsen as can be seen by a comparison of Fig. 6a with Figs. 6b and 6c. Moreover, additional phase formation within the grains is observed at $1200{ }^{\circ} \mathrm{C}$ (Fig. 6c) within the deformed matrix (indicated by changes of orientation contrast by localized deformation). The hexagonal Laves phase (patterns are similar to that in Fig. 3a and are included in the online supplementary) and an unknown phase (electron patterns in Fig. 7) could be identified as the secondary phases developing and coarsening during deformation at $1000{ }^{\circ} \mathrm{C}$ as well as $1200{ }^{\circ} \mathrm{C}$. The patterns of the unknown phase exhibit similar zone axes (indicated by arrows) to those of the unknown phase observed in the same temperature range during the solution annealing experiments. Nevertheless, the zone axis distances in the case of Fig. $7 \mathrm{~b}$ are slightly higher indicating changing lattice parameter ratios or lattice angles. This might be attributed to the different time scales for the compression tests at high temperature and for the solution annealing experiments. In accordance to the evaluation of the homogenized material, the Laves phase is enriched in $\mathrm{Cr}$ while the unknown phase exhibits a solute content similar to the solid solution. The local chemical analysis is included in Tab. 1.

Despite a comparatively low number of investigated grains, the orientation distribution plotted as contours in the inverse pole figure in Fig. 8 reveals an increase of orientation density between $\langle 001\rangle$ and $\langle 111\rangle$ crystallographic axes parallel to the compression direction as deformation temperature and, thus, plastic strain is increased. This can be explained by pencil glide being the predominant deformation mechanism. The $\langle 111\rangle$ crystallographic axes seem to be the common slip directions. For the commonly observed slip systems of bcc metals, namely with a $\langle 1 \overline{1} 1\rangle$ slip direction and slip planes of type $\{110\},\{121\}$, or $\{132\}$, a rotation of the compression direction under single slip from an arbitrary orientation within the standard triangle towards the trace between $\langle 001\rangle$ and $\langle 111\rangle$ is expected. The corresponding orientation changes are illustrated in Fig. 9.

\section{Conclusions}

This study provides the following main results regarding microstructure and deformation at elevated temperature of an equiatomic Nb-Mo-Cr-Ti-Al high-entropy alloy:

- The analysis of the microstructure of arc-melted Nb-Mo-Cr-Ti-Al subsequent to homogenization treatments reveals that the dendritic-like as-cast microstructure can be transformed into an equiaxed microstructure with minor secondary phases by annealing at $1300{ }^{\circ} \mathrm{C}$ under Ar atmosphere for $20 \mathrm{~h}$. The formation of the hexagonal modification of the $\mathrm{Cr}_{2} \mathrm{Nb}$ Laves phase can be suppressed by a homogenization temperature of $1300^{\circ} \mathrm{C}$ and above. 
- Compression tests reveal a maximum strength of $\approx 1 \mathrm{GPa}$ and increasing ductility up to a plastic strain of $24 \%$ with increasing test temperature up to $1200{ }^{\circ} \mathrm{C}$. During compression testing at $1000{ }^{\circ} \mathrm{C}$ as well as $1200{ }^{\circ} \mathrm{C}$, secondary phases are formed and coarsen, respectively.

- The analysis of fiber texture components subsequent to uniaxial compression testing at elevated temperatures suggests that $\mathrm{Nb}-\mathrm{Mo}-\mathrm{Cr}-\mathrm{Ti}-\mathrm{Al}$ deforms by dislocation slip, forming the common combined $\langle 001\rangle$ and $\langle 111\rangle$ fiber texture components along the compression direction. These can be explained in terms of the orientation change during slip deformation on slip systems with common $\langle 111\rangle$ slip direction.

\section{Acknowledgements}

The authors gratefully acknowledge the financial support by the Deutsche Forschungsgemeinschaft (DFG), grant no. HE 1872/31-1. AK thanks the Carl Zeiss Foundation for financial support by a postdoc grant. This work was partly carried out with the support of the Karlsruhe Nano Micro Facility (KNMF, www.knmf.kit.edu), a Helmholtz Research Infrastructure at Karlsruhe Institute of Technology (KIT, www.kit.edu). The authors acknowledge the chemical analysis by ICP-OES at the Institute for Applied Materials (IAMAWP), Karlsruhe Institute of Technology (KIT). Furthermore, we would like to express our gratitude to $\mathrm{S}$. Seils for experimental support.

\section{References}

[1] Yeh, J.-W.; Chen, S.-K.; Lin, S.-J.; Gan, J.-Y.; Chin, T.-S.; Shun, T.-T.; Tsau, C.-H. \& Chang, S.-Y.: "Nanostructured High-Entropy Alloys with Multiple Principal Elements: Novel Alloy Design Concepts and Outcomes" in Advanced Engineering Materials 6 (2004) 299-303

[2] Yeh, J.-W.; Chen, Y.-L.; Lin, S.-J. \& Chen, S.-K.: "High-Entropy Alloys - A New Era of Exploitation" in Materials Science Forum 560 (2007) 1-9

[3] Tsai, M.-H.: "Physical Properties of High Entropy Alloys" in Entropy 15 (2013) 53385345

[4] Tsai, M.-H. \& Yeh, J.-W.: "High-Entropy Alloys: A Critical Review" in Materials Research Letters 2 (2014) 107-123

[5] Zhang, Y.; Zuo, T. T.; Tang, Z.; Gao, M. C.; Dahmen, K. A.; Liaw, P. K. \& Lu, Z. P.: "Microstructures and properties of high-entropy alloys" in Progress in Materials Science 61 (2014) 1-93

[6] Northcott, L.: "Molybdenum" (1956), Butterworths Scientific Publications, London 
[7] Yu, X. J. Yu \& Kumar, K. S.: "The tensile response of Mo, Mo-Re and Mo-Si solid solutions" in Int. Journal of Refractory Metals and Hard Materials 41 (2013) 329-338

[8] Sturm, D.; Heilmaier, M.; Schneibel, J. H.; Jéhanno, P.; Skrotzki, B. \& Saage, H.: "The influence of silicon on the strength and fracture toughness of molybdenum" in Materials Science and Engineering A 463 (2007) 107-114

[9] Senkov, O. N. \& Semiatin, S. L.: "Microstructure and properties of a refractory highentropy alloy after cold working" in Journal of Alloys and Compounds 649 (2015) 1110-1123

[10] Senkov, O.; Wilks, G.; Miracle, D.; Chuang, C. \& Liaw, P.: "Refractory high-entropy alloys" in Intermetallics 18 (2010) 1758-1765

[11] Senkov, O.; Wilks, G.; Scott, J. \& Miracle, D.: "Mechanical properties of Nb25Mo25Ta25W25 and V20Nb20Mo20Ta20W20 refractory high entropy alloys" in Intermetallics 19 (2011) 698-706

[12] Zhang, B.; Gao, M. C.; Zhang, Y.; Yang, S.; Guo, S. M.: „Senary refractory high entropy alloy MoNbTaTiVW“

[13] Senkov, O; Senkova, S.; Woodward, C. \& Miracle, D. B.: "Low-density, refractory multi-principal element alloys of the $\mathrm{Cr}-\mathrm{Nb}-\mathrm{Ti}-\mathrm{V}-\mathrm{Zr}$ system: Microstructure and phase analysis" in Acta Materialia 61 (2013) 1545-1557

[14] Senkov, O.; Senkova, S.; Miracle, D. \& Woodward, C.: "Mechanical properties of lowdensity, refractory multi-principal element alloys of the $\mathrm{Cr}-\mathrm{Nb}-\mathrm{Ti}-\mathrm{V}-\mathrm{Zr}$ system" in Materials Science and Engineering A 565 (2013) 51-62

[15] Senkov, O.; Scott, J.; Senkova, S.; Miracle, D. \& Woodward, C.: "Microstructure and room temperature properties of a high-entropy TaNbHfZrTi alloy" in Journal of Alloys and Compounds 509 (2011) 6043-6048

[16] Senkov, O.; Scott, J.; Senkova, S.; Meisenkothen, F.; Miracle, D. \& Woodward, C.: "Microstructure and elevated temperature properties of a refractory TaNbHfZrTi alloy" in Journal of Materials Science 47 (2012) 4062-4074

[17] Senkov, O. \& Woodward, C.: "Microstructure and properties of a refractory NbCrMo0.5Ta0.5TiZr alloy" in Materials Science and Engineering A 529 (2011) 311-320

[18] Senkov, O. N.; Zhang, F. \& Miller, J. D.: "Phase Composition of a CrMo0.5NbTa0.5TiZr High Entropy Alloy: Comparison of Experimental and Simulated Data" in Entropy 15 (2013) 3796-3809

[19] Poletti, M. G.; Fiore, G.; Szost, B. A. \& Battezzati, L.: "Search for high entropy alloys in the X-NbTaTiZr systems (X=Al, Cr, V, Sn)" in Journal of Alloys and Compounds 620 (2015) 283-288 
360 [20] Couzinié, J.; Dirras, G.; Perrière, L.; Chauveau, T.; Leroy, E.; Champion, Y. \& Guillot,

361 I.: "Microstructure of a near-equimolar refractory high-entropy alloy" in Materials Letters 126

$362 \quad$ (2014) $285-287$

363 [21] Senkov, O.; Woodward, C. \& Miracle, D.: "Microstructure and Properties of Aluminum364 Containing Refractory High-Entropy Alloys" in JOM 66 (2014) 2030-2042

365 [22] Yang, X.; Zhang, Y.; Liaw, P. K.: „Microstructure and Compressive Properties of $366 \mathrm{NbTiVTaAl}_{\mathrm{x}}$ High Entropy Alloys" in Procedia Engineering 36 (2012) 292-298

367 [23] Lin, C. M.; Juan, C. C.; Chang, C. H.; Tsai, C. W.; Yeh, J. W.: "Effect of Al addition on 368 mechanical properties and microstructure of refractory $\mathrm{Al}_{\mathrm{x}} \mathrm{HfNbTaTiZr}$ alloys" in Journal of 369 Alloys and Compounds (2015) 100-107

370 [24] Gorr, B.; Azim, M.; Christ, H.-J.; Mueller, T.; Schliephake, D. \& Heilmaier, M.: "Phase 371 equilibria, microstructure, and high temperature oxidation resistance of novel refractory high372 entropy alloys" in Journal of Alloys and Compounds 624 (2014) 270-278

373 [25] Zhang, Y.; Zhou, Y. J.; Lin, J. P.; Chen, G. L.; Liaw, P. K.: „Solid-Solution Phase 374 Transformation Rules for Multi-component Alloys" in Advanced Engineering Materials 10 $375 \quad$ (2008) 534-538

376 [26] Zhang, Y.; Yang, X.; Liaw, P. K.: „Alloy Design and Properties Optimization of High377 Entropy Alloys“ in JOM 64 (2012) 830-838

378 [27] Guo, S.; Ng, C.; Lu, J.; Liu, C. T.: „Effect of valence electron concentration on stability 379 of fcc or bec phase in high entropy alloys" in Journal of Applied Physics 109 (2011) 103505

380 [28] Gorr, B.; Azim, M.; Christ, H.-J.; Chen, H.; Szabo, D. V. \& Heilmaier, M.:

381 "Microstructure evolution in a new refractory high-entropy alloy Mo-W-Al-Cr-Ti" in 382 Metallurgical and Materials Transactions A (2015) submitted

383 [29] Laurent-Brocq, M.; Akhatova, A.; Perrière, L.; Chebini, S.; Sauvage, X.; Leroy, E. \& 384 Champion, Y.: "Insights into the phase diagram of the CrMnFeCoNi high entropy alloy" in 385 Acta Materialia 88 (2015) 355-365

386 [30] Slater, J. C.: "Atomic radii in crystals" in The Journal of Chemical Physics 41 (1964) $387 \quad 3199-3204$

388 [31] Humphreys, F. J. \& Hatherly, M.: "Recrystallization and Related Annealing 389 Phenomena", Elsevier, Oxford (2004)

\section{Captions}

391 Tab. 1: Composition of the investigated alloy in different conditions determined by EDX. $392 \uparrow$ Composition determined by ICP-OES (unbalanced) for comparison. Dendritic and 
interdendritic regions are shown in the inset of Fig. 2a in detail. O content was determined to be 92 ppm in the as-cast state. $\mathrm{N}$ content was below the detection limit. * Phase located at the grain boundaries (see insets in Fig. 2c and d) and ** located within the grains (see Fig. 2c).

Fig. 1: SEM micrographs (BSE, orientation and composition contrast) of the microstructure of $\mathrm{Nb}-\mathrm{Mo}-\mathrm{Cr}-\mathrm{Ti}-\mathrm{Al}$ in the: a) as-cast and annealed conditions after heat treatment at b) $1100{ }^{\circ} \mathrm{C}$, c) $1200{ }^{\circ} \mathrm{C}$ and d) $1300{ }^{\circ} \mathrm{C}$ for $20 \mathrm{~h}$, respectively. All major micrographs are taken at the same magnification. Inset magnification is specified, respectively. The inset in (b) highlights the morphology of the at least three different phases at higher magnification. The insets in (c) and (d) show secondary phases with continuous as well as acicular morphology at the grain boundaries. The dark grain boundary phase in (c) is assigned to the EBSD pattern in Fig. $5 \mathrm{~g}$.

Fig. 2: Background subtracted XRD patterns of cross sections of Nb-Mo-Cr-Ti-Al in different conditions: a) full pattern and b) section of the pattern with logarithmic intensity scale. Bragg positions of bcc structures with varying lattice parameters (provided in $\mathrm{nm}$ ) are indicated by dashed lines in (a). Bragg positions of the hexagonal Laves phase are highlighted according to the labels in (b) - positions with little intensity were excluded. Intensities may be influenced by limited number of grain orientations within the samples. The lines, indicating the lattice constant variation, are extended to the diffraction patterns of the annealed state in order to ease comparison.

Fig. 3: EBSD patterns with corresponding zone axes of Nb-Mo-Cr-Ti-Al taken at $20 \mathrm{kV}$ on samples in different conditions (a complete set of patterns for all phases is included in the online supplementary). The Laves phase is the hexagonal modification of $\mathrm{Cr}_{2} \mathrm{Nb}\left(\mathrm{MgZn}_{2}\right.$ prototype, Strukturbericht designation C14).

Fig. 4: Stress-strain dependence of quasistatic compression tests at: a) room temperature, $400{ }^{\circ} \mathrm{C}$ and $600{ }^{\circ} \mathrm{C}$ as well as b) $800{ }^{\circ} \mathrm{C}, 1000^{\circ} \mathrm{C}$ and $1200{ }^{\circ} \mathrm{C}$. Fracture is highlighted by $\mathrm{X}$. Arrows indicate tests deliberately stopped.

Fig. 5: Orientation imaging microscopy on longitudinal sections of $\mathrm{Nb}-\mathrm{Mo}-\mathrm{Cr}-\mathrm{Ti}-\mathrm{Al}$ quasistatically deformed in compression: a) initial condition and deformed at b) $400{ }^{\circ} \mathrm{C}$, c) $800{ }^{\circ} \mathrm{C}$, d) $1000{ }^{\circ} \mathrm{C}$ and e) $1200^{\circ} \mathrm{C}$. Compression direction is vertical and the color code corresponds to the inverse pole figure of the compression direction (inset in (b)). The maps are of the same size and observed using a step size of $5 \mu \mathrm{m}$.

Fig. 6: Detailed SEM micrographs (BSE, orientation and composition contrast) of Nb-Mo-Cr$\mathrm{Ti}$-Al subsequent to deformation at: a) $800^{\circ} \mathrm{C}$, b) $1000^{\circ} \mathrm{C}$, and $1200^{\circ} \mathrm{C}$. All SEM micrographs are taken at the same magnification.

Fig. 7: EBSD patterns with corresponding zone axes of Nb-Mo-Cr-Ti-Al taken at $20 \mathrm{kV}$. A complete set of patterns for all phases is included in the online supplementary.

Fig. 8: Orientation distribution as contours in the inverse pole figures of the compression direction of $\mathrm{Nb}-\mathrm{Mo}-\mathrm{Cr}-\mathrm{Ti}-\mathrm{Al}$ quasistatically deformed in compression: a) initial condition, 
430 deformed at b) $400{ }^{\circ} \mathrm{C}$, c) $800{ }^{\circ} \mathrm{C}$, d) $1000{ }^{\circ} \mathrm{C}$, and e) $1200{ }^{\circ} \mathrm{C}$. Scale in multiples of the 431 random distribution (inset in (a)) is kept constant.

432 Fig. 9: a) Maximum Schmid factors (active slip system under single slip) of the pencil slip 433 systems with common $\langle 1 \overline{1} 1\rangle$ slip direction and $\{110\},\{121\}$, and $\{132\}$ slip planes presented 434 in the inverse pole figure of the compression direction. b) Rotation of the compression 435 direction, indicated by arrows, in dependence of the initial orientation of a single crystal. 436 Under compression load, the compression direction tends to rotate towards to slip plane 437 normal. Dashed lines indicate the connection of slip plane normals when multiple slip is 438 preferred.

439 Tab. 2: Yield stress $\sigma_{0.2}$, maximum strength $\sigma_{\max }$ and obtained plastic strain before fracture $\varepsilon_{\mathrm{p}}$ 440 as a function of temperature during compression tests; (X) marks those compression tests 441 which ended due to fracture of the respective sample 